\title{
Analysis of Economic-Technical Potential of Renewable Power Sources for the Establishment of National Renewable Energy Center in Ninh Thuan Province, Vietnam
}

\author{
Vu Minh Phap ${ }^{2}$, Doan Van Binh ${ }^{2}$, Nguyen Hoai Nam, ${ }^{2,}$ A. V. Edelev ${ }^{1}$, M. A. Marchenko ${ }^{3}$ \\ ${ }^{1}$ Melentiev Energy Systems Institute SB RAS, Irkutsk, Russia \\ ${ }^{2}$ Institute of Energy Science, Vietnam Academy of Science and Technology, Hanoi, Vietnam \\ ${ }^{3}$ Institute of Computational Mathematics and Mathematical Geophysics SB RAS, Novosibirsk, Russia
}

\begin{abstract}
Currently, Vietnam's energy source structure is being changed by which renewable energy sources play more important role to meet the electricity demand and reduce greenhouse gas emissions from fossil energy sources. Vietnam's energy development strategy determines to build some renewable energy centers, of which Ninh Thuan is the first province designated to become a national renewable energy center. This is based on Ninh Thuan's endowment as a province having the largest renewable energy potential in Vietnam. Development of a large renewable energy center allows power system planners to overcome the mismatch in timescales associated with developing transmission power grid and renewable energy generation. Besides, renewable energy center can facilitate a significant pipeline of large-scale renewable energy and storage projects. However, Ninh Thuan province is far away from the major load centers of Vietnam so the calculation and analysis of economic indicators need to be studied. This paper will present the results of the analysis of economic indicators of major renewable electricity sources in Ninh Thuan (onshore wind power, offshore wind power, solar power) to provide scientific arguments for developing a renewable energy center in Vietnam. Also the paper addresses the problem of the large-scale penetration of renewable energy into the power system of Vietnam. The proposed approach presents the optimization of operational decisions in different power generation technologies as a Markov decision process. It uses a stochastic base model that optimizes a deterministic lookahead model. The first model applies the stochastic search to optimize the operation of power sources. The second model captures hourly variations of renewable energy over a year. The approach helps to find the optimal generation configuration under different market conditions.
\end{abstract}

\section{Introduction}

The overall global renewable power capacity increased to around $2,378 \mathrm{GW}$ by the end of 2018 and achieved more than $33 \%$ of the world's total installed power generating capacity [1]. An estimated new renewable power capacity of $181 \mathrm{GW}$ was installed worldwide in 2018, in which, the total capacity of solar power accounted for $55 \%$ of renewable capacity additions, followed by wind power (28\%) [1]. The power system can receive a large proportion of renewable energy without using fossil fuels and nuclear power with the role of running "baseload", based on the flexibility of the electricity system, power grid connection, advanced technology solutions such as ICT (Information and communications technology), power storage systems and virtual power plants. It is not only helping to balance the change in the electricity generation stage but also optimizes the power system and reduces generation costs. As a result, some countries successfully control peak loads or surpassing the target of $100 \%$ of electricity produced from renewable energy.

There is a huge difference between renewable energy centers (wind and solar power) and traditional power centers such as a thermal power center in a national power system.This is because the peculiarities of its primary energy source. When developing a thermal power center, the preferred conditions for choosing a location are near large load centers or strong power grid or infrastructure (coal ports, for example). In the case of the renewable energy (RE) center, the preferred condition is the geographical areas with high solar radiation or good wind speed and efficiency in land use. This leads to the challenges of synchronizing and optimizing the transmission and distribution grids so that RE resources can be fully utilized in the considered geographical areas to reduce transmission losses as the load centers are usually far from the RE source. Some countries have been building large RE centers such as Asia RE Hub - AREH [2] in Western Australia and RE

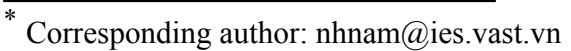


Zone [3] of Texas, USA. A large RE center (RE Hub or $\mathrm{RE}$ Zone) is a geographic area supporting cost-effective renewable energy (RE) development, including highquality RE resources, suitable topography, and strong developer interest. Development of a large RE center allows power system planners to overcome the difference in timescales associated with developing transmission power grid and RE generation. Besides, RE Hub or RE Zone can release a significant pipeline of large-scale renewable energy and storage projects.

Vietnam's electricity consumption increased steadily in recent years, from $90 \mathrm{TWh}$ in 2010 [4] to $227 \mathrm{TWh}$ in 2019 [5], with an annual growth rate of about $11 \%$ /year. At the same time, the power system's maximum installed capacity also raised from about $20000 \mathrm{MW}$ in 2010 [5] to about $55000 \mathrm{MW}$ in 2019 [6]. It is forecasted that Vietnam's electricity demand will achieve about 570 billion kWh by 2030 [7]. Currently, Vietnam is changing energy source structure, in which potential renewable energy sources play an important role to meet the electricity demand and reduce greenhouse gas emissions from fossil energy sources. It is expected that the solar power would reach 4,000 MW in 2025, and 12,000 MW by 2030 while the wind power 's capacity may increase to 2,000 MW by 2025, and 6,000 MW by 2030 [8]. The actual installed solar power capacity at the end of 2019 reached about 5,6 GW [9] while a total wind power capacity installed about 425 MW [10]. The feed-intariffs (FIT) for solar and wind power project were introduced at 7.09 cent $\$ / \mathrm{kWh}$ for ground-mounted PV project and 7.69 cent $\$ / \mathrm{kWh}$ for floating solar projects [11], 8.5 cent $\$ / \mathrm{kWh}$ for onshore wind and 9.8 cent $\$ / \mathrm{kWh}$ for offshore wind [12].

Vietnam's energy development strategy determines to build some renewable energy centers, of which Ninh Thuan is the first province designated to become a national renewable energy center as the province has the largest renewable energy potential in Vietnam. The national renewable energy center established in Ninh Thuan will play an important role in supporting the development of the renewable power industry in Vietnam.

However, Ninh Thuan province is distanced from the major load centers of Vietnam so the calculation and analysis of economic indicators need to be studied. This paper will present the results of the analysis of economic indicators of major renewable electricity sources in Ninh Thuan (onshore wind power, offshore wind power, solar power) to provide scientific arguments for developing a renewable energy center in Vietnam.

\section{Potential of solar and wind energy source in Ninh Thuan province}

\subsection{Geographical site}

Ninh Thuan, located in the southern part of Vietnam Central Coastal region, borders Khanh Hoa in the north, Binh Thuan in the south, Lam Dong in the west, East sea in the East.
The province has total natural surface of 3,360 sq. kilometers, 7 administrative units including 1 city and 6 districts. The city of Phan Rang - Thap Cham, as provincial city, constitutes a political, economic and cultural center of the province, distant from Hochiminh City by $350 \mathrm{~km}$, from international Cam Ranh airport by $60 \mathrm{~km}$, from the city of Nha Trang by $105 \mathrm{~km}$ and from $\mathrm{Da}$ Lat by $110 \mathrm{~km}$ with favorable conditions for circulations in service of socio-economic development.

\subsection{Solar energy potential}

Ninh Thuan is located in an area with the annual average solar radiation of about $5.5 \mathrm{kWh} / \mathrm{m}^{2}$.day, the average number of sunshine hours is about 2,600-2,800 hours per year (equivalent to 200 sunny days/year), and a total solar power installation scale of about 1,500 MW. In Ninh Thuan, the area of Ninh Phuoc district and Thuan Nam district where having large solar energy potential can be effectively exploited [13].

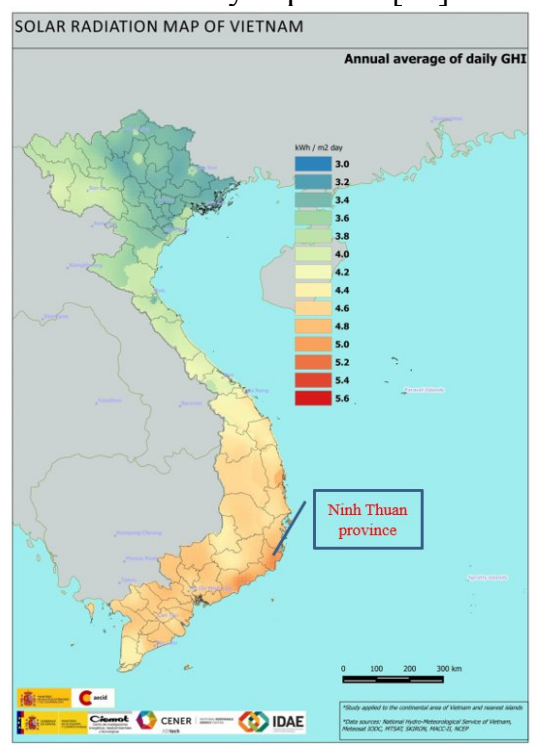

Fig. 1. Solar energy potential of Ninh Thuan province [6]

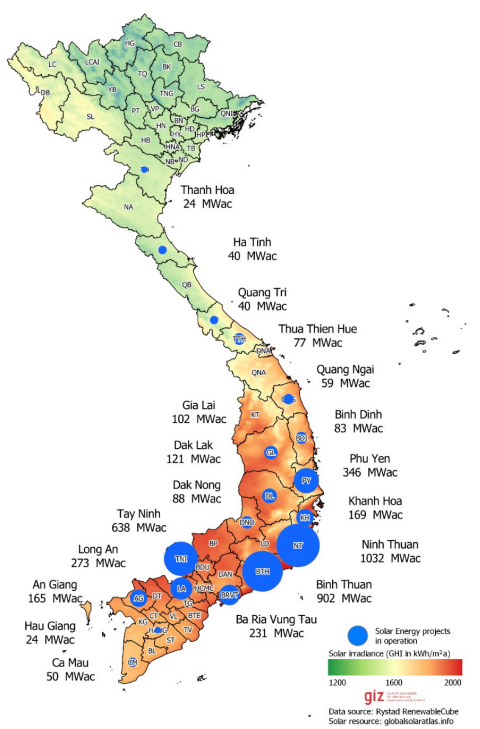

Fig 2. Installed solar power capacity in Vietnam [6] 
Until August 2019, the number of completed solar power projects in Ninh Thuan was highest in Vietnam with the total installed capacity of about $1032 \mathrm{MW}$ [6].

\subsection{Wind energy potential}

Ninh Thuạn province also has the largest wind power potential in Vietnam with the annual average wind speed of about $7 \mathrm{~m} / \mathrm{s}$ at the height above $65 \mathrm{~m}$. The whole province has 14 potential wind regions with about 8,000 ha, concentrated mainly in three districts of Ninh Phuoc, Thuan Nam and Thuan Bac. Especially, storms in Ninh Thuan is not much and the wind blows steadily for 10 months at a speed of $6.4-9.6 \mathrm{~m} / \mathrm{s}$, ensuring stability for wind power development. The technical wind power potential and the highly feasible area of Ninh Thuan are $1,442 \mathrm{MW}$ with 21,642 ha [14].

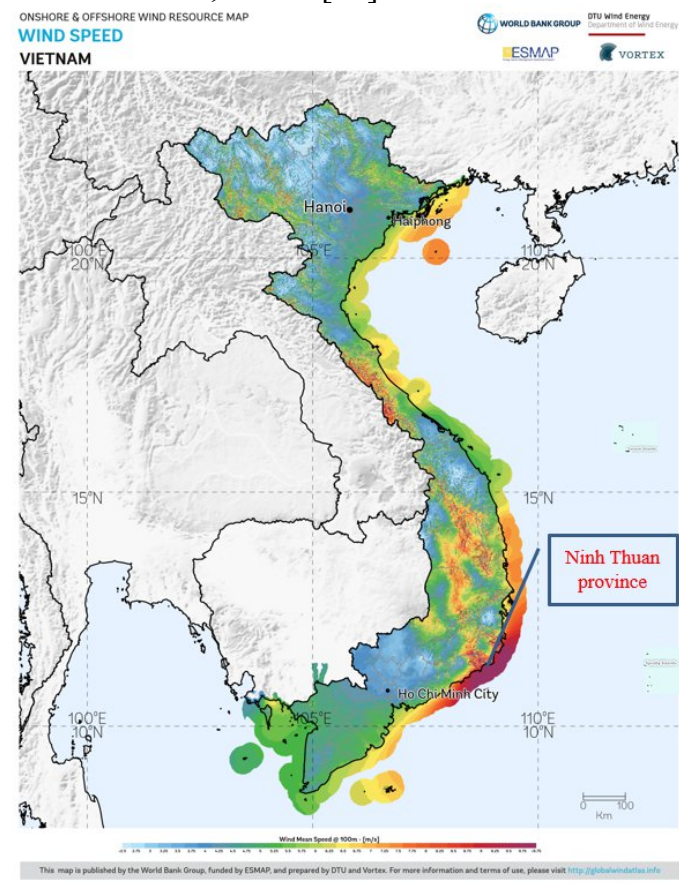

Fig 3. Wind energy potential in Vietnam [15]

Up to August 2019, Ninh Thuan achieved the largest number of commissioned wind power projects in Vietnam with the total installed capacity of about 109 MW as shown in Figure 4 [6].

\subsection{Methodology}

In this study, the electricity of solar farm is calculated by using PVSYST program $[16,17]$ while the output from wind turbine is determined by using design data of wind farm projects in planning of wind power development in Ninh Thuan [14].

The economic potential was determined by considering the annualized investment costs and the annual O\&M costs. The goal is the calculation of the minimum Feed in tariff (FIT) level. Currently, the level of FIT can be calculated on the basis of a calculation of the levelized cost of electricity (LCOE) produced from renewable energy (RE) projects [19]. By which, the investor can recover the different costs (capital, O\&M, fuel, financing) while realizing a return on his investment that depends on the assumed financing costs.

LCoE has been utilized to assess the average lifetime costs of providing one MWh for a range of power production technologies or power savings. The cost elements comprising the $\mathrm{LCoE}$ include investment costs, fuel costs, operation and maintenance costs, environmental externalities and system costs for solar and wind power plants. $\mathrm{LCoE}$ is given by the following formula:

$$
L C O E=\frac{\sum_{t=1}^{n}\left(I_{t}+\boldsymbol{M t}+\boldsymbol{F t}\right)}{\sum \frac{\boldsymbol{E}_{t}}{(1+\boldsymbol{r})^{t}}}
$$

In which:

$\mathrm{I}_{\mathrm{t}}$ : investment cost by the year $\mathrm{t}$

$\mathrm{M}_{\mathrm{t}}$ : Operation and Maintenance cost by the year $\mathrm{t}$

$\mathrm{F}_{\mathrm{t}}$ : Fuel cost by the year $\mathrm{t}$

$\mathrm{E}_{\mathrm{t}}$ : Electricity production by the year $\mathrm{t}$

r: discount rate

$\mathrm{n}$ : project lifetime (year)

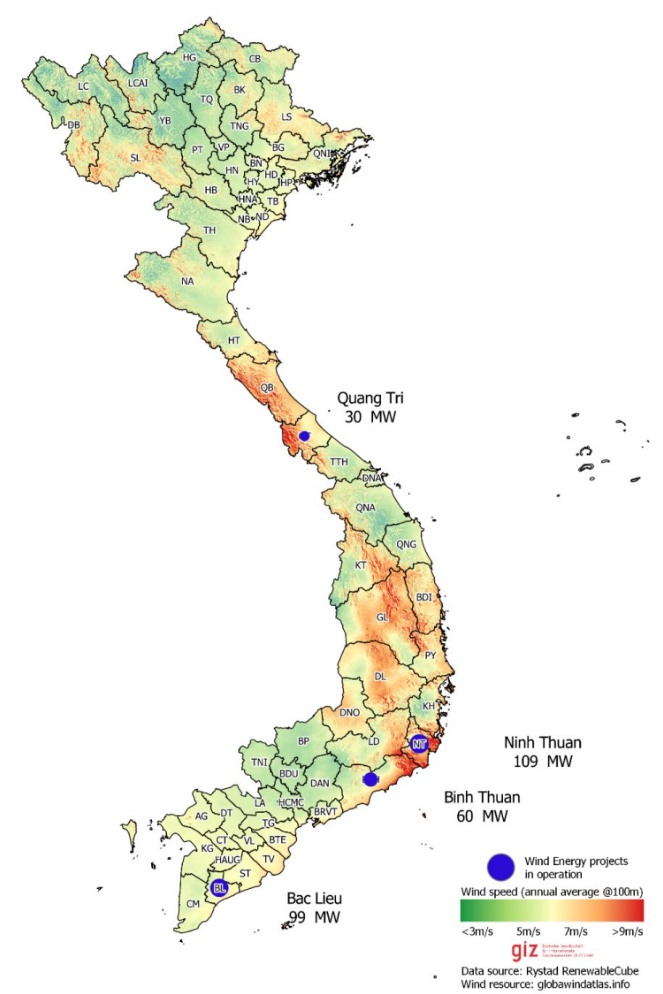

Fig 4. Installed wind power capacity in Vietnam [6]

\subsection{Results}

The key parameters are used for the calculations are shown in Table 1.

Table 1. Input parameters

\begin{tabular}{|c|c|c|c|}
\hline Parameters & $\begin{array}{c}\text { Ground- } \\
\text { mounted } \\
\text { PV power }\end{array}$ & $\begin{array}{c}\text { Onshore } \\
\text { wind power }\end{array}$ & $\begin{array}{c}\text { Offshore } \\
\text { wind power }\end{array}$ \\
\hline
\end{tabular}




\begin{tabular}{|l|r|r|r|}
\hline $\begin{array}{l}\text { Initial } \\
\text { Investment } \\
\text { Cost (\$) }\end{array}$ & $25,278,015$ & $53,892,216$ & $66,723,695$ \\
\hline $\begin{array}{l}\text { Operations } \\
\text { and } \\
\begin{array}{l}\text { Maintenance } \\
\text { Costs (\$) }\end{array}\end{array}$ & 126,390 & $1,077,844$ & $1,334,474$ \\
\hline $\begin{array}{l}\text { O\&M Growth } \\
\text { Rate (\%) }\end{array}$ & 2 & 2 & 2 \\
\hline $\begin{array}{l}\text { Capacity } \\
\text { (MW) }\end{array}$ & 30 & 30 & 30 \\
\hline $\begin{array}{l}\text { Annual } \\
\text { Electricity } \\
\text { Output } \\
\text { (MWh) }\end{array}$ & $48,450^{*}$ & 73,584 & 86,724 \\
\hline $\begin{array}{l}\text { Project } \\
\text { Lifespan } \\
\text { (years) }\end{array}$ & 25 & 25 & 25 \\
\hline $\begin{array}{l}\text { Discount Rate } \\
\text { (\%) }\end{array}$ & 6 & 6 & 6 \\
\hline
\end{tabular}

*Note: Power degradation of solar power is no more than $2.5 \%$ in the first year, thereafter $0.7 \%$ per year until $25^{\text {th }}$ year.

The LCOE or minimum FIT of major renewable electricity sources in Ninh Thuan (onshore wind power, offshore wind power, solar power) is evaluated in Table 2.

Table 2. Economic indicators calculation

\begin{tabular}{|l|r|r|r|}
\hline \multicolumn{1}{|c|}{ Parameters } & $\begin{array}{c}\text { Ground- } \\
\text { mounted } \\
\text { PV power }\end{array}$ & $\begin{array}{c}\text { Onshore } \\
\text { wind power }\end{array}$ & $\begin{array}{c}\text { Offshore } \\
\text { wind power }\end{array}$ \\
\hline $\begin{array}{l}\text { Net present } \\
\text { value (NPV) (\$) }\end{array}$ & $27,074,753$ & $69,214,650$ & $84,046,360$ \\
\hline $\begin{array}{l}\text { LCOE } \\
\text { centsUS/kWh) }\end{array}$ & 5.1 & 7.9 & 8.2 \\
\hline
\end{tabular}

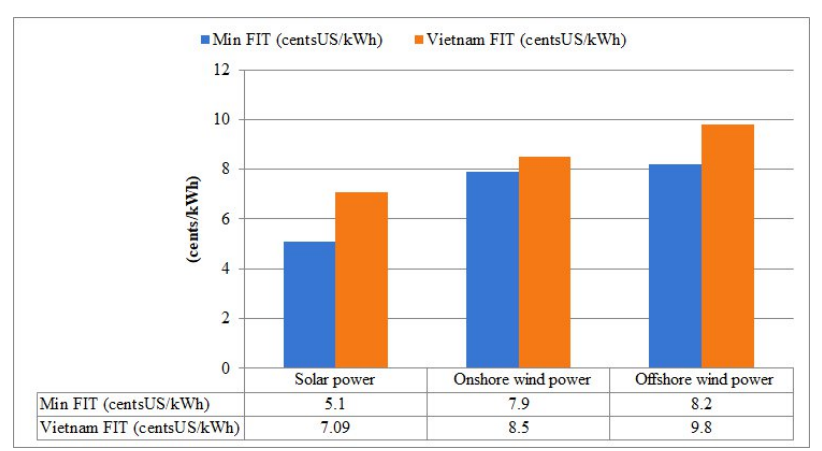

Fig 5. Minimum FIT versus Vietnam FIT

Figure 5 presents the comparison results between minimum FIT of onshore wind power, offshore wind power, solar power projects in Ninh Thuan with existing Vietnam FIT of these projects in Vietnam. The min FIT of onshore wind power in Ninh Thuan is closer with Vietnam FIT than solar power and offshore wind power.

\section{Generation expansion planning}

The planning models are the traditional tool to analyse future developments in the energy sector. The capacity planning problem in the power systems has been divided into demand forecasting, distribution expansion planning, transmission expansion planning, and generation expansion planning (GEP). For each capacity planning problem, the time horizon can be divided into long-term, medium-term, or short-term studies [20]. Short-term planning is associated with day-to-day system operation. Medium-term planning involves the maintenance of system assets. Long-term planning relates to new capacity additions [21].

GEP is a power plant mix problem that identifies types, location, and construction time of new generation technologies, which should be added to the existing system in order to meet the power demand over a specific planning horizon $[20,22]$. The contemporary, systematic, and robust GEP should consider [23]:

- Integration of electric vehicles in power systems,

- Integration of short-term operational aspects into decision making,

- Power and fossil fuel systems interdependence,

- Energy storage and demand-side impacts on GEP,

- Policy implications on power investments, highlighting the role of supply of security.

The GEP models can be classified according to time horizon (static and dynamic), handling of uncertainties (deterministic and stochastic), network topology (the single-node or centralised and network constrained), and market structure (regulated and deregulated) [20].

The GEP is usually an optimisation problem in which the aim is to distinguish the optimal size, type of generation unit, and commitment time of new generating facilities so as to satisfy the power demand at least cost over a planning horizon [20].

\subsection{Generation expansion planning with high share of renewable energy}

The RE resources create for the power systems' operation some operational challenges for GEP due to the following feature of their stochastic nature [24-26]:

- $\quad$ RE variability requires flexible generation that can ramp up and down quickly,

- The intermittency makes the output from RE sources uncertain.

- Power quality and voltage stability issues connected with RE variability that needs to be assessed, controlled, observed and mitigated appropriately,

These three aspects (variability, intermittency, and grid stability issues) necessitate a paradigm change in GEP models that assess the impact of increased penetration of RE [27-29]. Traditional GEP models have mostly focused on the conventional power plant whose 
operation and planning can be easily conducted by varying fuel inputs to match variability on the load side $[20,30]$. To address the operational challenges the grid might require additional levels of reserves [31-33]. Another way to mitigate these challenges is the adoption of storage units [34-36].

There are a lot of works that have included the integration of RE sources in GEP problem [37-42].

\subsection{Generation expansion planning with high share of renewable energy}

The RE resources create for the power systems' operation some operational challenges for GEP due to the following feature of their stochastic nature [24-26]:

- $\quad$ RE variability requires flexible generation that can ramp up and down quickly,

- The intermittency makes the output from RE sources uncertain.

- Power quality and voltage stability issues connected with RE variability that needs to be assessed, controlled, observed and mitigated appropriately,

These three aspects (variability, intermittency, and grid stability issues) necessitate a paradigm change in GEP models that assess the impact of increased penetration of RE [27-29]. Traditional GEP models have mostly focused on the conventional power plant whose operation and planning can be easily conducted by varying fuel inputs to match variability on the load side $[20,30]$. To address the operational challenges the grid might require additional levels of reserves [31-33]. Another way to mitigate these challenges is the adoption of storage units [34-36].

There are a lot of works that have included the integration of RE sources in GEP problem [37-42].

\subsection{Decision-making in energy planning}

Most of the decisions to be made by energy sector decision-makers are fed by information which is usually subject to uncertainties [43]. There are different types of uncertainty: Gaussian noise, heavy-tailed distributions, bursts, rare events, temporal uncertainty, lagged information processes, and model uncertainty [44]. The combination of the uncertainty types with decisions that may be binary, discrete, continuous or categorical, scalar or vector creates a virtually unlimited range of problems [45].

There are much uncertainty handling methods developed for dealing with uncertain parameters: stochastic, possibilistic, hybrid and etc. The main difference between them is a way they choose to describe the uncertainty of the model's inputs. And they are similar in the attempt to quantify the influence of inputs on model's outputs [46].

\subsubsection{Problem formulation}

Our approach for solving GEP problem is based on the stochastic optimization framework $[45,47]$ that divides decision-making into the following five components: states, actions, exogenous information, transition function and objective function. Similarly to [48, 49], the proposed approach presents the optimization of operational decisions in GEP as a Markov decision process. It uses a stochastic base model that optimizes a deterministic lookahead model. The first model applies the stochastic search to optimize the operation of power sources and the second model captures hourly variations of RE over a year.

The simplified structure of the energy sector of Vietnam is represented as a network $G=(N, A)$, where $N$ is the set of the nodes and $A$ is the set of arcs. The node $i \quad N$ represents a point of demand and/or supply of energy, and the arc $(i, j) A$ is a transmission line.

A set of power generation technologies $O$ consists of two subsets: fossil fuel-fired facilities and RE sources. $R$ denotes the RE subset. The fossil fuels constitute the set $F \cdot q \quad O$ is a power generation technology and $k \quad F$ is a fossil fuel. $T$ is the number of periods (hours) in the planning horizon where $t \quad T$ is a time period.

\subsubsection{The base model}

The base model is intensively based on the work [50]. The additional objectives and constraints are adopted from studies [51-53].

The current state of the Vietnamese energy sector in the period $t$ may be represented as

$$
s_{t}=\left(d_{i t}, h_{i q t}, b_{k t}, o_{k t}, p_{t}\right) i \quad N, q \quad R, k \quad F, t \quad T
$$

where $d_{i t}$ is the load/demand (MW) at the node $i$ in the period $\boldsymbol{t}, h_{i a t}$ is the corresponding hourly capacity factor for each RE technology $q$ in the node $i$ during the period $t, b_{k t}$ is the local production (kTOE) of the fuel $k$ in the period $t, o_{k t}$ is the cost (\$/kTOE) of the fuel $k$ import in the period $t, p_{t}=\left(d_{i t^{\prime}}, h_{i q t^{\prime}}, b_{k t^{\prime}}, o_{k t^{\prime}}\right)$ is forecast for $t^{\prime}>t$.

The decisions variables in the period $t$ may be represented as

$$
x_{t}=\left(g_{i q t}, x_{i j t}, v_{i t}\right) i \quad N,(i, j) \quad A, q \quad O, k \quad F, t \quad T
$$

where $g_{\text {iqt }}$ is the generation amount (MW) of the technology $q$ at the node $i$ in the period $t ; x_{i j t}$ is the flow (MW) through the arc $(i, j)$ in the period $\boldsymbol{t}$, and 
$v_{i t}$ is the unmet demand (MW) at the node $i$ in the period $t$.

The set of feasible decisions in the period $t$ is defined by the following constraints:

- Node power balance equation: the generation plus flow from other nodes is equal to the sum of demand, shortage and flow to other nodes at the node $i \in N$ in the period

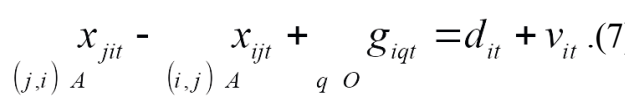

- Fossil fuels demand in the period $t$ : The fuel $k$ will be either imported or taken from local markets

$$
{ }_{i N q O} w_{q t} g_{i q t} \quad u_{k t}+b_{k t} ; k \quad F, t \quad T,(8)
$$

where $w_{q t}$ is the consumption of fuel (kTOE/MW) for the technology $q$ in the period $t$.

- Power generation limit on each conventional technology in the node during the period :

$$
g_{\text {iqt }} \quad y_{\text {iqt }} ; i \quad N, q \quad O \backslash R, t \quad T \text {.(9) }
$$

where $y_{i q t}$ is the total capacity (MW) of the technology $q$ at the node $\boldsymbol{i}$ in the period $\boldsymbol{t}$.

- Power generation limit on each RE technology $\sigma$ in the node during the period :

$$
g_{\text {iqt }} \quad h_{\text {iqt }} y_{\text {iqt }} ; i \quad N, q \quad R, t \quad T .(10)
$$

- Power transmission limit on each arc $(i \quad i)$ in the period :

$$
x_{i j t} \quad p_{i j t} ;(i, j) \quad A, t \quad T .(11)
$$

- Nonnegativity: no negative values are permitted for the decision variables

$$
g_{i q t}, x_{i j t}, u_{k t}, v_{i t} \quad 0,(12)
$$

where $i \quad N, q O,(i, j) \quad A, k F$, and $t \quad T$.

The transition from the state $S_{t}$ to the successor state $s_{t+1}$ is determined by the function $s^{M}$

$$
s_{t+1}=s^{M}\left(s_{t}, x_{t}, w_{t+1}\right) ; t \quad T
$$

where $w_{t+1}$ is uncontrolled exogenous process defined as the random variables that capture the stochastic updating of wind, solar, demand and cost forecasts. The $w_{t}$ is modeled as changes of $d_{i t}, h_{i a t}, b_{k t}$, and $o_{k t}$.
The total cost of the energy sector functioning $s_{t}$ over the period $t$ consists of operation and transmission costs, environmental impact, imports of fuel, and unmet demand cost:

- Operational and transmission costs: this objective function is defined as the total present value sum of the operation and maintenance costs

$$
f_{1}(t)={ }_{i N q O} q_{i q t} g_{i q t}
$$

In this objective, $q_{\text {iqt }}$ is the operation and maintenance cost (\$/MW) of the technology $q$ at the node $\boldsymbol{i}$ in the period $\boldsymbol{t}$.

- Fossil fuel import: the goal is to minimize the total amount of fuel imports

$$
f_{2}(t)={ }_{k F} o_{k t} u_{k t} .
$$

- Unmet demand: the goal is to minimize the total power shortage

$$
f_{3}(t)={ }_{i N} l_{t} v_{i t}
$$

where $l_{t}$ is the cost (\$/MW) of not satisfying the demand in the period $t$.

The total cost over the period $t$ may defined as

$$
c\left(s_{t}, x_{t}\right)=f_{l=1}^{3} f_{l}(t)
$$

The policy represented by the function $x_{t}\left(s_{t}\right)$ makes hourly planning decisions and returns the feasible decision $x_{t}$ for any system state $s_{t}$. The overall goal of the stochastic base model is to find the best policy. Since $S_{t}$ is a random variable, the objective function would be written as the minimization of the expected sum of total cost over the entire time horizon $T$

$$
\text { mine }{ }_{t T} c\left(s_{t}, x_{t}\left(s_{t}\right)\right) \text {. }
$$

\subsubsection{The lookahead model}

The deterministic model is the policy $\left.x_{t}^{L A}\left(s_{t}\right) \quad\right)$ with the lookahead horizon as the tunable parameter [49]. It determines the decisions by solving the optimization problem

$$
\arg \min _{x_{t}}^{t+}{ }_{t^{\prime}=l=1}^{3} f_{l}\left(t^{\prime}\right)
$$


where the set of feasible decisions $x_{t}$ is defined by constraints (5)-(19) for each $t^{\prime}$ with $t \quad t^{\prime}<t+\min (T-t, \quad)$.

The solving the lookahead model in (19) is not an optimal policy but it helps obtain robust behaviour by tuning using the base model.

\subsection{Parallelization}

Finding the optimal solution of the GEP problem can require running some hundreds evaluations of the total yearly cost [48]. Each evaluation is expensive computationally, since it solves a linear program that looks into the future for each hour in a year (i.e. 8760 rather big linear programs).

The future implementation of the proposed approach for solving GEP problem will use parallelization as a base feature to provide these evaluations. The approach will be implemented on the top of PARMONC - the library of easy-to-use programs that was implemented on highperformance clusters of the Siberian Supercomputer Center. The main features of the PARMONC are as follows:

- $\quad$ it is suitable for the massively parallel stochastic simulation for a wide range of applications,

- $\quad$ it is a software framework to parallelize stochastic simulation to be applied without knowledge of MPI language.

The PARMONC effectively launches stochastic simulation on supercomputers with different architectures. Also, it is scalable from current supercomputers to more powerful ones up to future exaflop supercomputers.

For example, each yearly assessment can be represented as 12 separate monthly evaluations, if a special distributed computing environment with parallel generator of pseudorandom numbers [54] is used.

\section{Conclusions}

In this study, the potential of solar power and wind power in Ninh Thuan province were presented with the annual average solar radiation of about $5.5 \mathrm{kWh} / \mathrm{m}^{2}$.day and wind speed of $6.4-9.6 \mathrm{~m} / \mathrm{s}$.

The economic indicators calculation shows that the minimum FIT of onshore wind power, offshore wind power, solar power projects in Ninh Thuan were lower than current Vietnam FIT. The gap between minimum FIT and Vietnam FIT of onshore wind power was smaller than offshore wind power, solar power projects.

The proposed generation expansion planning approach presents the optimization of operational decisions in different power generation technologies as a Markov decision process. It uses a stochastic base model that optimizes a deterministic lookahead model. The first model applies the stochastic search to optimize the operation of power sources. The second model captures hourly variations of renewable energy over a year.

The approach helps to find the optimal generation configuration under different market conditions. Also, the approach takes into account the following types of constraints: flow balance constraints in the network with demand covering, power generation and transmission limit, availability of local fossil fuels production, system reliability requirements, maximum and minimum shares of RE resources, and energy supply security requirements.

Acknowledgements: This study was funded by Ninh Thuan province under the project "Development of Ninh Thuan province into national renewable energy center". The development of the stochastic optimization model for generation expansion planning was supported by the Russian Foundation of Basic Research and Government of Irkutsk Region, project no. 20-47-380002.

\section{References}

1. REN21, "Renewables 2019 Global Status Report GSR", (2019).

2. Hurlbut, D. and Getman, D, "Greening the Grid: Implementing Renewable Energy Zones for Integrated Transmission and Generation Planning." Webinar, (2015).

3. Asian Renewable Energy Hub, "New proposal would provide renewable energy and manufacturing boost to Indonesia; Australia's wind and solar resources to generate renewable energy", (2018).

4. https://www.iea.org/data-and-statistics?country VIETNAM\&fuel=Energy $\% 20$ consumption\& indicator=Electricity $\% 20$ consumption

5. https://www.ceicdata.com/en/indicator/vietnam/elect ricity-production

6. Nguyen Thai Son, "Increasing the proportion of renewable energy sources in Vietnam's Electricity Development Planning", in Proceeding of International Scientific Conference "Model to Develop Ninh Thuan Province into The National Renewable Energy Center, Solutions and Criteria", Ninh Thuan province, (2019).

7. http://ievn.com.vn/UserFile/Files/News/NLVNE.pdf

8. Prime Minister, "National Power Development Master Plan (PDP VII) for the 2011- 2020 period, with a vision for 2030", (2016).

9. https://www.statista.com/statistics/1006138/vietnam -total-solar-energy-capacity/

10. Minh Ha-Duong, Sven Teske, Dimitri Pescia, Mentari Pujantoro, "Options for wind power in Vietnam by 2030 ”, (2020). 
11. Vietnamese Deputy Prime Minister, Decision 13/2020/QD-TTg on Mechanisms to Promote the Development of Solar Power Projects in Viet Nam, (2020).

12. Vietnamese Prime Minister, Decision No 39/2018/QĐ-TTg for adjusting and supplementing a number of articles of the Decision No 37/2011/QĐTTg on the mechanism to support the development of wind power projects in Vietnam, (2018).

13. Planning of solar power development in Ninh Thuan, (2017).

14. Planning of wind power development in Ninh Thuan in the period 2011-2020, vision to 2030, (2013).

15. Joost Sissingh, Eric Arends (Wind Minds), Wind Energy Potential Vietnam, (2018).

16. Vu Minh Phap, Nguyen Thuy Nga, "Feasibility Study of Rooftop Photovoltaic Power System For A Research Institute Towards Green Building In Vietnam". EAI Endorsed Transactions on Energy Web, pp. 1-9, (2020).

17. Vu Minh Phap, Le Thi Thuy Hang. "Comparison of Central Inverter and String Inverter for Solar Power Plant: Case Study in Vietnam". Journal of Nuclear Engineering \& Technology. 9(3):11-23p, (2019).

18. Giap LUONG Ngoc, Maeda Takao, Vu Minh Phap, Nguyen Binh Khanh, Hồ Thị Bích Ngọc and B. T. Trung. "Comparative Study Of Velocity Deficit Calculation Methods For A Wind Farm In Vietnam." IOSR Journal of Engineering, Vol 7 (9), (2017).

19.

20. Babatunde O M, Munda J L and Hamam Y 2019 A comprehensive state-of-the-art survey on power generation expansion planning with intermittent renewable energy source and energy storage Int. J. of Energy Res 1-30

21. Das P, Mathur J, Bhakar R and Kanudia A 2018 Implications of short-term renewable energy resource intermittency in long-term power system planning Energy strategy reviews 22 1-15

22. Sadeghi H, Rashidinejad M and Abdollahi A 2017 A comprehensive sequential review study through the generation expansion planning Renewable and Sustainable Energy Reviews 67 1369-1394

23. Koltsaklis N E and Dagoumas A S 2018 State-ofthe-art generation expansion planning: A review Applied energy 230 563-589

24. Bylling H C, Pineda S and Boomsma T K 2018 The impact of short-term variability and uncertainty on long-term power planning Annals of Operations Research 1-25

25. Jones L E 2017 Renewable energy integration: practical management of variability uncertainty and flexibility in power grids Academic Press

26. Oree V Hassen S Z S and Fleming P J 2017 Generation expansion planning optimisation with renewable energy integration: A review Renewable and Sustainable Energy Reviews 69 790-803
27. Senatla M and Bansal R C 2018 Review of planning methodologies used for determination of optimal generation capacity mix: the cases of high shares of PV and wind IET Renewable Power Generation 12(11) 1222-1233

28. Welsch M, Howells M, Hesamzadeh M R Ó, Gallachóir B et. al 2015 Supporting security and adequacy in future energy systems: The need to enhance long-term energy system models to better treat issues related to variability International Journal of Energy Research 39(3) 377-396

29. Poncelet K, Delarue E, Duerinck J, Six D and D'haeseleer W 2014 The importance of integrating the variability of renewables in long-term energy planning models In BAEE Research

30. Després J, Hadjsaid N, Criqui P and Noirot I 2015 Modelling the impacts of variable renewable sources on the power sector: Reconsidering the typology of energy modelling tools Energy 80 486-495

31. Bessa R, Moreira C, Silva B and Matos M 2014 Handling renewable energy variability and uncertainty in power systems operation Wiley Interdisciplinary Reviews: Energy and Environment 3(2) 156-178

32. Vithayasrichareon P, Riesz J and MacGill I 2017 Operational flexibility of future generation portfolios with high renewables Applied energy 206 $32-41$

33. Moreira A, Pozo D, Street A and Sauma E 2017 Reliable renewable generation and transmission expansion planning: Co-optimizing system's resources for meeting renewable targets IEEE Trans Power Syst 32(4) 3246-3257

34. Akinbulire T O, Oluseyi P O and Babatunde O M 2014 Techno-economic and environmental evaluation of demand side management techniques for rural electrification in ibadan nigeria Int $\mathrm{J}$ Energy Environ Eng 5(4) 375-385

35. Denholm P and Hand M 2011 Grid flexibility and storage required to achieve very high penetration of variable renewable electricity Energy Policy 39(3) $1817-1830$

36. Castillo A and Gayme D F 2014 Grid-scale energy storage applications in renewable energy integration: A survey Energy Conversion and Management 87 885-894

37. Ding J and Somani A 2010 April A long-term investment planning model for mixed energy infrastructure integrated with renewable energy In 2010 IEEE Green Technologies Conference pp 1-10

38. Li S, Coit D W and Felder F 2016 Stochastic optimization for electric power generation expansion planning with discrete climate change scenarios Electric Power Syst Res 140 401-412

39. Farghal S A and Aziz M A 1988 Generation expansion planning including the renewable energy sources IEEE Transactions on Power Systems 3(3) 816-822 
40. Hu Z, Jewell W T 2013 Optimal generation expansion planning with integration of variable renewables and bulk energy storage systems In: 2013 1st IEEE Conference on Technologies for Sustainability (SusTech) pp 1-8

41. Aghaei J, Akbari M, Roosta A, Gitizadeh M and Niknam T 2012 Integrated renewable-conventional generation expansion planning using multiobjective framework IET Gener Transm Distrib 6(8) 773-784

42. Pina A, Silva C A and Ferrão P 2013 Highresolution modeling framework for planning electricity systems with high penetration of renewables Applied Energy 112 215-223

43. Conejo A J, Carrion M and Morales J M 2010 Decision Making Under Uncertainty in Electricity Markets Springer

44. Powell W 2014 Energy and Uncertainty: Models and Algorithms for Complex Energy Systems AI Magazine 35(3) 8-21

45. Powell W B 2019 A unified framework for stochastic optimization European Journal of Operational Research 275(3) 795-821

46. Soroudi A and Amraee T 2013 Decision making under uncertainty in energy systems: State of the art Renewable and Sustainable Energy Reviews 28 376384

47. Powell W B and Meisel S 2015 Tutorial on stochastic optimization in energy - Part I: Modeling and policies IEEE Transactions on Power Systems 31(2) 1459-1467

48. Khazaei J and Powell W B 2015 SMART-Invest: a stochastic dynamic planning for optimizing investments in wind solar and storage in the presence of fossil fuels. The case of the PJM electricity market Energy Systems 1-27

49. Meisel S and Powell W B 2017 Dynamic decision making in energy systems with storage and renewable energy sources In Advances Energy System Optimization 87-101

50. Meza J L C, Yildirim M B and Masud A S 2007 A model for the multiperiod multiobjective power generation expansion problem IEEE Trans Power Syst 22(2) 871-878

51. Tekiner H, Coit D W and Felder F 2010 A Multiperiod multi-objective electricity generation expansion planning problem with Monte-Carlo simulation Electr. Pow. Syst. Res. 80(12) 1394-1405

52. Kies A, Schyska B, Viet D T, Heinemann L B D and Schramm S 2017 Large-Scale Integration of Renewable Power Sources into the Vietnamese Power System Energy Procedia 125 207-213

53. Noorollahi E, Fadai D, Ghodsipour S H and Shirazi M A 2017 Developing a new optimization framework for power generation expansion planning with the inclusion of renewable energy - A case study of Iran J. Renew Sustain Energy 9(1)
54. Marchenko, M.A., Mikhailov, G.A. Distributed computing by the Monte Carlo method. Autom Remote Control 68, 888-900 (2007). 